тронную закладную, а также требований к их формату" [Электронный ресурс - КонсультантПлюс] URL: http://www.consultant.ru/law/hotdocs/54660.html/

12 Будущее блокчейна в России [Электронный ресурc] URL: https://bits.media/na-rbw-obsudilibudushchee-blokcheyna-v-rossii/

13 Идея создания крипторубля [Электронный ресурc] URL: https://info.finance/obzorkriptovalyut/kriptorubl-nacionalnaya-kriptovalyuta-rossii

\title{
THE DEVELOPMENT OF THE DIGITAL ECONOMY IN THE BANKING SECTOR WITH BLOCKCHAIN
}

\author{
(C) 2020 Timofeeva Arina Yuryevna \\ Student \\ Samara State University of Economics \\ E-mail: arina_tim007@mail.ru
}

Keywords: digital economics, end-to-end technologies, blockchain, smart contract, cryptocurrency, "Masterchain".

Today economics is digital because an increasing number of operations becomes online in the banking sector. It is worth to consider the principle and essence of blockchain and its participation in Russia.

УДК 336.748.12

Код РИНЦ 06.00.00

\section{ЦИФРОВАЯ ИНФЛЯЦИЯ КАК СЛЕДСТВИЕ РАЗВИТИЯ ЦИФРОВОЙ ЭКОНОМИКИ}

\author{
() 2020 Тимофеева Арина Юрьевна* \\ студент \\ Самарский государственный университет \\ E-mail: arina_tim007@mail.ru
}

Ключевые слова: цифровая инфляция, уравнение Фишера, цифровые технологии, антиинфляционный эффрект, интернет-торговля.

С развитием цифрровой экономики появляются сквозные технологии, которые значительно упрощают нам жизнь. Участвуя почти во всех ссрерах экономической отрасли, они оказывают влияние на цены. Поэтому данная статья посвящена цифровой инфляции как феномену, возникшем в современном мире.

Началом развития цифровой экономики можно считать конец 20в. Сейчас данная сфера представляет собой одну из самых развивающихся отраслей современной экономики. Так,

* Научный руководитель - Лунин Игорь Анатольевич, старший преподаватель. 
благодаря новым цифрровым технологиям (блокчейн, BIG DATA, искусственный интеллект и др.) ускоряется проведение финансовых операций, появляются новые возможности осуществления безналичных платежей. В связи с существенным влиянием цифрровых технологий на все ссреры экономической деятельности, включая и денежное обращение, в экономике появился термин "цифровая инфляция"1. Как такие нововведения оказывают влияние на инфляцию и каковы их последствия, рассмотрим в материале данной статьи.

Инфрляция представляет собой процесс обесценивания денег, т.е. потерю их покупательной способности из-за заполнения каналов обращения избыточными бумажными средствами сверх реальных потребностей народного хозяйства². Происходит повышение общего уровня цен на рынке в течение некоторого периода времени. Получается, что на один и тот же объем денежных средств через промежуток времени можно будет приобрести меньше товаров или услуг, чем раньше. Так, например, с появлением кредитных денег, происходит автоматическая эмиссия. И, как следствие, появляется инфляция. Согласно количественной теории, стоимость денег прямо пропорциональна их количествуз:

где $M$ - количество денег в обращении;

$$
M * V=P * Q \text {, }
$$

$V$ - скорость оборота денежных средств;

$P$ - цена на товары и услуги;

$Q$ - количество произведенных товаров.

В соответствии с вышеприведенным уравнением И.Фишера при увеличении объема товарной стоимости, произведенной стране, необходимо увеличение объема денежной массы, находящейся в обращении для беспрепятственного товарообмена экономики. А в ситуации, когда масса денег увеличивается без роста товарной стоимости, процесс ее увеличения приводит к росту цен и снижению стоимости денег, то есть инфляции. Таким образом, цены на рынке стремительно начинают расти, и темпы инсрляции увеличиваются. Аналогичный механизм может проявляться и при появлении новых фрорм и инструментов организации денежного обращения, так как их проявление существенно повышает скорость денежного обращения. Согласно уравнению И.Фишера, повышение скорости денежного обращения даже при существующей денежной массе способно повлиять на увеличение общего уровня цен, при условии неизменности объема реального производства.

С применением новых цифровых технологий существенно меняется структура издержек предлагаемых покупателям товаров и услуг. Происходит существенное снижение транзакционных и информационных издержек участников рынка, а это, в свою очередь, повышает степень конкуренции и оказывает сдерживающее влияние на цены. Это касается и цифровых технологий в области денежного обращения. То есть наблюдаем прямо противоположный эффект. Теперь благодаря сети Интернет увеличивается степень информированности покупателей о товарах. Таким образом, потребители имеют возможность не только узнать о ценах на продукцию от разных производителей, но и выбрать среди предложенного то, что будет выгодно им.

Новые цифровые технологии по своей сути являются антиинфрляционным последствием. Приведем пример. Технология блокчейн, которая не только позволяет безопасно хранить данные, но и с помощью уменьшения документооборота увеличивает скорость проведения операций, сегодня активно поддерживается банками. Так, время на обработку транзакции (покупки какого-либо товара, перевод средств) существенно изменяется. 
Если раньше этот процесс мог занять несколько дней, то теперь всего от 2 до 4 часов. Также благодаря данной технологии все данные об операции направляются участнику сети, т.е. все происходит без посредников. Следовательно, можно сделать вывод, что снижаются транзакционные издержки, являющиеся затратами на поиск, обработку информации при заключении сделок, оформлении договоров. При их снижении следует понижение стоимости данной операции и, как следствие, повышается качество услуг для потребителя 4 .

Таким образом, темпы инфрляции не повышаются согласно определению, а наоборот, сокращаются, происходит переход к дефляции, к повышению покупательной способности денег и, соответственно, их реальной стоимости. Если рассматривать экономику, с введенными в ней информационными технологиями в краткосрочном периоде, то несомненно можно отметить проявляющийся эффект дефрляции.

Однако если рассматривать долгосрочный период, что в России, где онлайнторговля не распространена так, как в странах Запада (доля в РФ составляет 30-40\% от офрлайн-торговли, тогда как в США - 70-80\%), цифрровая инфрлция не заметна. Так как сквозные технологии развиты не повсеместно, то и антиинфляционный эфффект, осуществляемый ими, не будет оказывать достаточного влияния на реальную инфляцию, которая давит на цены.

В США доля интернет-торговли растет очень быстро по сравнению с другими странами (в 2019 году составила примерно 80\%). Эфффект Amazon, названный в честь одноименного онлайн-магазина (Amazon.com), присутствует при проведении транзакций по Интернету5. Так как все больше и больше покупателей используют именно этот сайт для совершения заказов, то и данный интернет гигант продолжает развиваться. Так, предположим, что "цифровая" инфляция в США отстает от "обычной" примерно на 1-1,5 п.п. (процентных пункта). Из-за развивающейся конкуренции между реальными и интернетмагазинами цены на продукцию в офрлайне выше, чем в онлайн-режиме, т.е. теперь отстает на 1,5-2,3 п.п. Следовательно, потребители будут приобретать товары по более низким ценам, стремясь сэкономить. Совокупный спрос на интернет продукцию будет расти быстрыми темпами. Так как покупка, продажа происходит через сеть, то снижаются издержки на содержание трудовых ресурсов (т.е. работников необходимо меньше, заработной платы также выплачивать нужно меньше). Поэтому сейчас в США возникает тенденция сокращения реальных магазинов и перевод их в онлайн-режим. Следствием такого положения в американской экономике является слишком низкая цифровая инфляция (более 3 п.п.), возникающая из-за увеличивающегося спроса именно на товары, которые можно заказать по Интернетуб.

Данная проблема касается непосредственно и деятельности центральных банков. Новые цифровые технологии организации денежного обращения имеют иную природу происхождения, нежели чем современные кредитные деньги. Именно поэтому с развитием сквозных технологий проходится менять методы и способы денежно-кредитной политики, а также находить новые пути ее осуществления.

Хочется отметить, что цифрровые технологии все в больше и больше применяются в нашей деятельности, а это, в свою очередь, безусловно очень важно для нашего будущего и экономики в целом. Но их применение и экономическое содержание в области денежного обращения должно быть учтено политикой центральных банков в области 
управления инфлляционными процессами в силу разностороннего характера воздействия на уровень цен, что поможет экономике в целом находиться в стабильном положении.

1 Сущность "цифровой инсрляции" [Электронный ресурc] URL: http://digitaleconomy.ru/mneniya/inflyatsiya-inflyatsii-v-usloviyakh-perekhoda-v-tsifrovuyu-formatsiyu

2 А.М. Лопухов Определение инфрляции // Словарь терминов и понятий по обществознанию. 9-е изд. 2016. 512 c.

3 Формула количественной теории денег [Электронный ресурc] URL: http://www.grandars.ru/student/finansy/kolichestvennaya-teoriya-deneg.html

${ }_{4}^{4}$ Функционирование блокчейна [Электронный ресурc] URL: http://bestinvestpro.com/blokchejnchto-eto-ponyatnym-yazykom/

5 Сущность эфффекта Amazon [Электронный ресурс] URL: https://www.entrepreneur.com/ article/325556

6 "Цифровая инфляция" в США [Электронный ресурc] URL: https://econs.online/articles/ekonomika/tsifrovaya-inflyatsiya/

\title{
DIGITAL INFLATION AS A RESULT OF THE DEVELOPMENT OF DIGITAL ECONOMY
}

\author{
(C) 2020 Timofeeva Arina Yuryevna \\ Student \\ Samara State University of Economics \\ E-mail: arina_tim007@mail.ru
}

Keywords: digital inflation, Fisher's equation, digital technology, anti-inflation effect, e-commerce.

Now economics is developing, therefore end-to-end technologies are appeared. They participate in almost all areas of the economic industry and wield influence on prices. This article is about digital inflation. It is phenomenon in modern economy.

УДК 330.12

Код РИНЦ 06.00.00

\section{ОСОБЕННОСТИ ОРГАНИЗАЦИИ ЛОГИСТИЧЕСКОЙ СИСТЕМЫ СБЫТА ТОРГОВЫХ ПРЕДПРИЯТИЙ}

\author{
(ㄷ 2020 Тойменцева Ирина Анатольевна \\ доктор экономических наук, доцент \\ Самарский государственный экономический университет \\ E-mail: tia67@rambler.ru
}

Ключевые слова: сбытовая деятельность, оптовая и розничная торговля, ассортимент, конкурентоспособность, реклама, транспортировка, логистические посредники. 